\title{
SGI: A Framework for Increasing the Sustainability of Gamification Impact
}

\author{
Alaa AlMarshedi, Gary B. Wills \\ School of Electronics and Computer \\ Science University of Southampton \\ Southampton, United Kingdom
}

\author{
Vanissa Wanick, Ashok Ranchhod \\ Winchester School of Art \\ University of Southampton \\ Winchester, United Kingdom
}

\begin{abstract}
Gamification is defined as the use of game design elements in non-gaming contexts. It is been getting a lot of attention in recent years. However, the amount of research undertaken on gamification is limited. One of the problems it faces is sustainability. Designers might overlook the elements that increase sustainability due to lack of a standard framework that contains the essential components to achieve that goal. This paper proposes a framework that aims to increase the sustainability of the desired impact of gamified applications. This framework contains the following components: flow, relatedness, purpose, autonomy and mastery in the design of gamified applications. The proposed framework will help to guide potential work in the field of games and gamification. In the future we aim to evaluate the framework further.
\end{abstract}

\section{Introduction}

Game applications extend beyond the scope of entertainment. In fact, it includes serious games, simulations and gamification. Since 2010, gamification, which is the use of game elements and techniques in a non-gaming context [1], has gained popularity. It is used to increase engagement and loyalty, motivate people, and shift behavior [2] In the past few years, gamification has been applied in many applications in several fields, including marketing [2], [3], education [4] and healthcare [5]

There existed many ways in which gamification can be implemented in order to enhance user's engagement. However, it is not always guaranteed that the implementation in its most basic form can achieve this goal. Hence, it is sometimes crucial to complement gamification with other techniques. For instance, recent research shows that including social elements to gamification can further enhance user's engagement [6]. However, the more the service is used and the longer people interact with it, the more they gain personal experience of the service, thus becoming an expert in the application [6].

According to Pink [7], there are four elements that alleviate motivation: relatedness, purpose, autonomy and mastery. However, applying these elements into gamification has not been adequately addressed in the literature. Moreover, it is necessary to understand how flow [8] can be integrated in the gamification process. Furthermore, mastery and autonomy are two important elements for the flow in gamification since they help in balancing users' skills with presented challenges. Additionally, storyline comes in conjunction with flow. In games, for example, the storyline can help to promote the player's immersion through meaningful challenges, impacting flow experiences [9]. Thus, it needs to be addressed as well as a mean to keep people engaged in the long term regarding the purpose of the application.

However, the impact of gamification might be temporary. Some research shows that the longer the gamified application is used, the less effect it has on its users [10]. Moreover, some designers might overlook the elements that increase the sustainability of gamification due to the lack of a standard framework that contains the essential components to achieve that goal.

This paper proposes a framework that increases the sustainability of the desired impact of gamified applications. This framework contains the following components: flow, relatedness, purpose, autonomy and mastery in the design of gamified applications. The proposed framework will help to guide future work in the field of games and gamification.

\section{Gamification}

Gamification is the use of game design techniques and mechanics in other fields. It is a design process that involves play, fun and user experience [11] through the application of game design elements into non-game contexts. Moreover, it can be applied in many fields and for different purposes [1]. For example, in e-government, gamification can be used to motivate and build citizenship actions through mobile applications that combine pervasive computing to non-leisure contexts, working with geo-location data and feedback loops to improve user participation [12]. Furthermore, from a business perspective, gamification can improve the engagement of users in actions related to services, products and/or brands [13]. In other applications, gamification can function as a way to improve longterm relationships, motivating users to interact with virtual and tangible rewards [14].

Moreover, McGonigal [15] in her book "Reality is Broken" argues that games have the power to fulfill human needs and solve real world problems. This reflection put games on a different standard. They are not only tools for entertainment, but also a source of inspiration, engagement and persuasion 
[16]. Furthermore, the emotional factor in games is powerful. A simple scoring system, for example, can motivate people to change behavior. In fact, once a game rewards users with positive feedback, give social support to actions and develop attitudes or behavior, it becomes a social actor in pervasive computing environments [16]. Persuasive technology is defined as any type of interactive computing system that is developed to influence people's attitudes or behaviors [16]. Furthermore, the ability to identify oneself with others and with the game is one of the most powerful persuasion principles [16] .

The boundaries between the two terms, game and gamification, are often blurred. One could ask is a gamified application a game or merely an application? According to [1], this limit is "empirical, subjective and social", and depends on the user's perceptions. The relationship between game elements and gamification does not transform every gamified system into a game. Essentially, game elements in the context of gamified applications should be considered as affordances to gameful experiences [1].

Gamification has proved to be successful in many fields. Having a clear end goal is one of the most important points for gamifying a system [17]. This way it can be measured to indicate if it is successful or not. However, this does not deny the fact that gamification systems reach a saturation point where they lose their appeal and therefore their effect.

Two of the main underlying concepts of gamification: motivation and engagement; both of which will be highlighted in the following paragraphs.

\subsection{Motivation in Gamification}

Motivation is one of the main concepts that gamification is built on [6]. There are two types of motivations that drive people's actions, intrinsic and extrinsic. Intrinsic motivation is related to the actions that are driven by an internal interest or enjoyment, while extrinsic motivation is conveyed by activities performed solely to gain a certain outcome regardless of the activity itself.

In addition, Krippendorff [18] differentiates extrinsic motivation as a way to reach objectives or achieve specific goals and intrinsic motivation as a process of engagement, without the suggestion an outcome, in which fun is mentioned as one feature of involvement. Both types are used in gamification. However, the latter could lead to an unsustainable gamified system, whereas the former can guide to a sustainable gamified system, since it satisfies an internal quest of an individual.

Considering the aspects of motivation and behavior design in the global society, gamification operates in very a similar way, setting goals and rules, rewarding winners and penalizing losers [19].
Thus, gamified applications tend to have some familiarity to the societal system.

Furthermore, motivation of an individual can result from four types of interactions while playing a game. These are explained by Lazzaro [20] and summarized in (see Table 1). This indicates that the individual motivations can be emphasized by social contexts and individual needs, which can be adopted in a creation of gamified system.

\section{Table 1. Keys of fun}

\begin{tabular}{|l|l|}
\hline Hard Fun & $\begin{array}{l}\text { Motivation to mastery, achievement } \\
\text { and challenge. }\end{array}$ \\
\hline Easy Fun & $\begin{array}{l}\text { Players want to be immersed into } \\
\text { fantasy worlds, exploration, and } \\
\text { adventure. }\end{array}$ \\
\hline $\begin{array}{l}\text { Serious } \\
\text { Fun }\end{array}$ & $\begin{array}{l}\text { People play games for excitement } \\
\text { and relief in a social context }\end{array}$ \\
\hline People Fun & $\begin{array}{l}\text { Players play games to cooperate, } \\
\text { compete or performance with other } \\
\text { participants. }\end{array}$ \\
\hline
\end{tabular}

In principle, motivational needs (e.g. competence, autonomy, and relatedness) are concepts borrowed from Self-Determination Theory (SDT) [21]. It can be applied in the context of gamified systems and services. This is due to the significant relationship between autonomy, satisfaction, intrinsic motivation, gameplay experience, and social meaning [1].

In addition, flow, which is a mental state of immersion in an activity, is one of the elements that could promote motivation. Moreover, flow is characterized by engrossed focus, complete involvement and enjoyment in the activity itself [7]. In fact, some research shows that it has a great impact on motivation [22]. This is especially because different gaming situations could satisfy different psychological needs, including power, achievement, information and relationship [23]. This means that elements of fun, enjoyment, control, autonomy and flow experiences should be relevant to the construction of intrinsic motivation.

\subsection{Engagement in Gamification}

In today's engagement economy, getting the attention of consumers is not enough [24]. It is necessary to drive meaningful experiences for people. In this context, engagement has been defined as a connection and a relationship between a consumer and a product or a service, which includes metrics like recency, frequency, duration, virality and ratings [13]. Consistently, Newbery and Farnham [25] define engagement as the way people interact and interpret the business values, including customer relationship over time and experiences delivered through touchpoints. However, can engagement be only related to time and repetition? 
Engagement can also be emotional, physical, intellectual, and spiritual and therefore can impact purchase repetition and positive word-of-mouth [26]. This is one aspect that could even influence behavioral actions that goes beyond the act of purchase by itself, including customer recommendations, web postings and different manifestations [27].

In gamification, engagement could be provided by game-design techniques. This is because games are considered as a combination of human nature and design, and not only entertainment, where the reward system is provided by the game itself [11]. Moreover, videogames offer elements that keep player's attention and interest, which make them tools for persuasive actions [16]. Although engagement has a strong link to time-related actions and sustainable conditions, it is necessary to understand how to enhance this state by providing a well-designed process of gamification. Considering previous research [13], one of the main issues gamified applications face is the long-term relationship with consumers.

Thus, the aim of this paper is to consider this opportunity to propose a framework that utilizes both concepts to produce sustainable gamification impact, which will be explained below.

\section{The Framework for Sustainable Gamification Impact (SGI)}

After painting a picture of the current situation of gamification and highlighting the lack of research regarding its sustainable effect, we suggest a number of elements that could influence the impact of gamification. The presented framework for Sustainable Gamification Impact (SGI) considers essentially three backgrounds that draws on Flow dimensions [8], Pink's elements to drive motivation [7] and SDT [21] (see Table 2).

As highlighted before, previous finding shows that in contexts involving gamified applications, perceived usefulness, and enjoyment and playfulness tend to fade and decrease on long-term relationship [13]. This relationship could be connected to three important concepts: motivation, flow and engagement. Motivation is the main concept of gamification [6]. It is related to autonomy, enjoyment and control [1], relatedness and competence [28], and mastery and purpose [7]. Consistently, flow is also related to competence or player's skills [8]. It is related to intrinsic motivation [22], especially through the process of engagement and involvement [18]. According to Csikszentmihalyi [8], intrinsic motivation is directly related to the development of skills. For example, people improve their skills because they enjoy doing one specific activity. In other words, intrinsic motivation is related to the performance of one action, through intrinsic and meaningful rewards.
Hence, this characteristic makes extrinsic rewards unsustainable. Thus, this aspect puts flow and motivation in the core of the gamification process. Furthermore, engagement is related to the repetition of one action [13] and user's involvement [18], [25]. For this reason, time is another important element to be considered as it is related to the user's engagement.

Therefore, the SGI framework proposes a focus on flow dimensions and motivational determinants in order to provide engaging and sustainable gamified experience (see Figure 1). Furthermore, mastery is something that is achieved by competence, skills, challenges and time. Therefore, it is shown as the "journey" in the outer circle. The representation of the framework should work as a spiral.

The SGI framework focuses on the user, and it starts by defining and identifying the user's purpose, relatedness and competence. These elements should be balanced and work in harmony. As the user achieves goals and master towards a single objective, he/she will be able to sustain their interest in the gamified application. For that, the designer should focus on establishing meaningful goals to the user. Also, pay more attention to the selection of elements that could help the user to improve.

The spiral shape of SGI represents an important concept; that the user will not return to the same point of the cycle. As the user masters and improves within the system, he becomes an expert.

The elements provided in Figure 1 are explained more detail in the following sections.

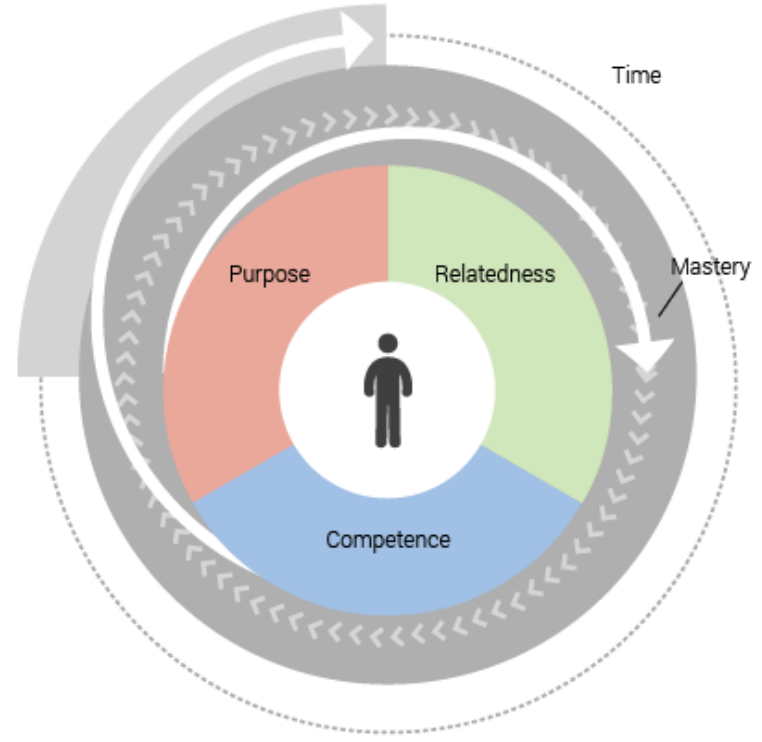

Figure 1. SGI Framework

\subsection{Flow}

By definition, flow takes place when people feel that they are totally involved in one action. It includes four components: control, attention, curiosity and intrinsic interest [8]. In this scenario, 
[8] argues that control is enhanced by the ability of the activity to be goal-oriented, delivering feedback to the user. These aspects would allow the individual to develop concentration and attention into one specific activity. Moreover, intrinsic interest is directly related to the ability of the user to avoid external influences, improving individual's concentration and attention. In addition, curiosity is supported by the capacity of the activity to promote discovery and creativity, bringing a new reality to the individual [8]. This aspect puts autonomy, intrinsic motivation, meaningful goals, feedback, concentration and novelty, as important elements for the implementation of flow experiences.

In essence, the "Flow Theory" describes a mental state that involves maximum focus and immersion in one activity. Figure 2 shows that while the difficulty and challenge (skills/time) are in flow state, people are neither anxious nor bored. For example, if one wants to learn a musical instrument, he/she will start the activity with no skills. Thus, the challenges and the goals should be achievable. However, he/she might improve his/her skills along time, through practice. In this situation, the challenges and difficulty need to follow people's competence and skills. Moreover, there are eight dimensions that take part of the flow experience. According to Csikszentmihalyi (1993), these include:

- "Clear goals and immediate feedback

- Balance between level of challenge and personal skills

- Merging of action and awareness

- Sense of control

- Focused concentration

- Loss of self-consciousness

- $\quad$ Time distortion

- Self-rewarding experiences" [29](see Table $2)$. Thus, the conception of flow has a clear relationship to significant and personal goals.

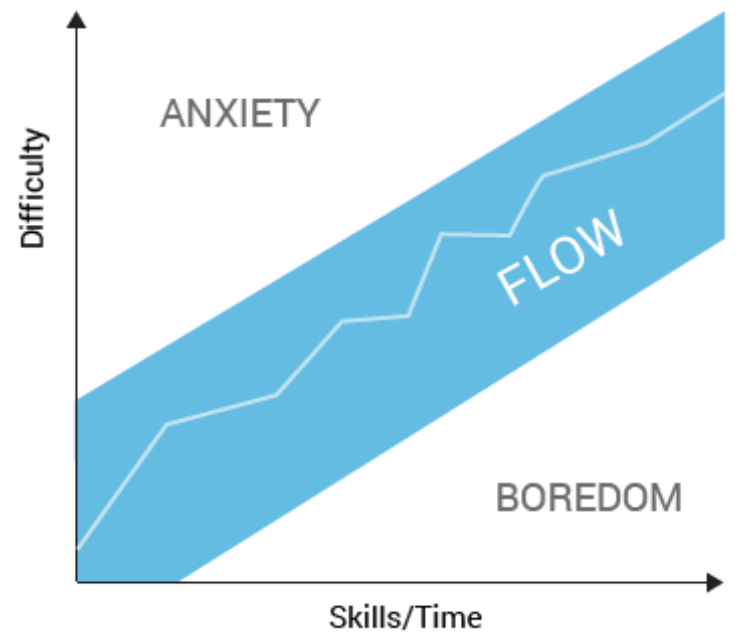

Figure 2. The Flow Theory [8]
In games, flow is represented by the combination of challenge and performance, regarding the player's skills [30]. For example, the concept of flow could be associated to positive affect that games creates to the user, suggesting that components such as the accomplishment of tasks, ability to concentration, clear goals, feedback, effortless involvement, control, alteration of the notion of time and disappearance of sense of the self during the flow experience, could inform affective game design [28].

In addition, flow has been related to the analysis of player's enjoyment while playing a game. For example, [31] applied the flow framework [8] in order to evaluate player's experiences and to identify elements that could make players engaged to the gameplay. Thus, flow could be associated with motivational aspects.

Furthermore, flow could affect the intention to play online games, especially if combined with social features [22]. Thus, this aspect could be reflected into gamified applications, balancing challenges and the ability to perform the action, within a social context.

\section{Table 2. Elements that impact the Gamification Process}

\begin{tabular}{|l|l|l|}
\hline $\begin{array}{l}\text { Flow dimensions } \\
{[8]}\end{array}$ & $\begin{array}{l}\text { Pink's } \\
\text { elements to } \\
\text { drive } \\
\text { motivation [7] }\end{array}$ & SDT [21] \\
\hline $\begin{array}{l}\text { Clear goals and } \\
\text { immediate } \\
\text { feedback }\end{array}$ & $\begin{array}{l}\text { Mastery, } \\
\text { Purpose }\end{array}$ & Competence \\
\hline $\begin{array}{l}\text { Balance between } \\
\text { level of challenge } \\
\text { and personal skill }\end{array}$ & Mastery & Competence \\
\hline $\begin{array}{l}\text { Merging of action } \\
\text { and awareness }\end{array}$ & $\begin{array}{l}\text { Mastery, } \\
\text { Autonomy }\end{array}$ & Autonomy \\
\hline $\begin{array}{l}\text { Sense of potential } \\
\text { control }\end{array}$ & Autonomy & Autonomy \\
\hline $\begin{array}{l}\text { Loss of self- } \\
\text { consciousness }\end{array}$ & Autonomy & Autonomy \\
\hline Time distortion & Autonomy & Autonomy \\
\hline $\begin{array}{l}\text { Autotelic or self- } \\
\text { rewarding } \\
\text { experience }\end{array}$ & Purpose & Autonomy \\
\hline
\end{tabular}

\subsection{Relatedness}

The term "relatedness" means the basic needs of interaction with others [32]. It is the feeling of belonging and connectivity with other people [28]. Moreover, it can be fulfilled in games through the creation of meaningful stories, providing a relatable experience to the users [32]. Thus, in gamified 
applications, relevant stories could also provide relatedness. For example, a story could be the background of the gamified system, bringing a meaningful social context to the individuals involved in the activity [32].

In addition, relatedness together with meaningful communities should be suitable for successful applications. In user experience design, relatedness is characterized by social situations and it is considered on the investigation of users' needs and positive emotions [33]. Moreover, Lazzaro [20] argues that fun is also related to people factor, represented by social interactions, especially through the use of multiplayer games. This means that the inclusion of social aspects to game-like activities is a way to promote positive experiences.

In gamified systems, social factors could influence the enjoyment of the application positively [1]. For example, Fitocracy, a gamified application for healthy activities, allows users to have friends following their activities, encouraging them to perform and achieve goals [1]. Although social actions are important to evoke relatedness, it is necessary to understand the implementation of them on the game design level. In this situation, elements such as updating personal status, making comments and joining groups could be a way to stimulate social interactions [1].

Furthermore, relatedness along with other human needs such as autonomy and competence could be considered factors in promoting intrinsic motivation. [28]. Consistently, this combination could also help gamified applications to perform efficiently, as motivational affordances [1].

\subsection{Purpose}

Purpose is related to autotelic experiences, composed by auto (self) and telos (goal or purpose). This means that an autotelic experience has a selffulfilling goal, making the whole rewarding journey [7]. It is an aspect of human condition that is related to a motive and meaningful goals. The purpose element should not be overlooked in situations that involve motivational attempts [22]. In gamification, a way to apply purpose is by the transformation of utilitarian approaches into hedonic or autotelic attempts [34]. This means that the gamified application should be less designed as a tool or a mean to itself and more developed as an intrinsic reward.

Therefore, purpose has a strong relationship not only to clear goals, but also to meaningful feedbacks, transforming the player's journey into a reward itself. For example, the important message of the feedback should be related to the achievement of the goal [7]. Hence, the implementation of significant and clear feedback is important to be considered.

In games, the utilization of feedback loops is represented by the balance of positive and negative factors inside the game as, for example, ending the game by giving a positive feedback to the player through a reward [20]. However, this balance should consider also the player's purpose and the other elements highlighted in the SGI framework. The "purpose" element by itself would not be sufficient to determine a sustainable gamified application, unless elements such as mastery, flow, autonomy and relatedness are designed in combination to clear goals and respective feedbacks.

Thus, in the SGI framework, purpose could be represented by the designation of meaningful goals and customizable goals and relevant feedback loops, regarding the user's goals.

\subsection{Autonomy}

Autonomy is when people feel the need to be in control of their life. According to the SDT, it is one of the premises of intrinsic motivation, involving control and choice [21]. Consistently, this aspect shows that people want to be in control of their tasks and could be related to a positive experience, leading to engagement [22]. Moreover, the ability of one application to promote sense of control to the user could help to provide flow experiences. This aspect puts autonomy as one important element in order to make people interested and engaged with one activity.

The voluntary aspect provided by games could promote a sense of autonomy, control and enjoyment, enhancing intrinsic motivational approaches [1]. This suggests that gamified applications should also carry the voluntary aspect borrowed from games, in order to provide autonomy and sense of control to the users [32].

\subsection{Mastery}

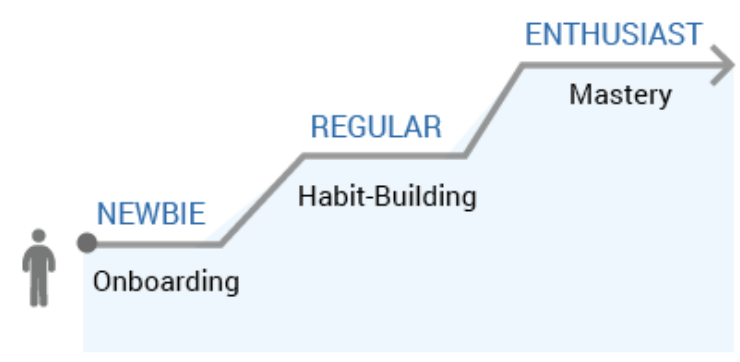

\section{Figure 3. Adapted from Amy Jo Kim's Player Journey [35]}

Mastery is considered as the desire of "getting better at something that matters" through engaging activities, especially when the activity itself is selfrewarding [22]. This means that mastery should be combined with autonomy and purpose, providing a whole and unique experience to the user. Moreover, well-designed games can promote learning through practice, which would help people to develop mastery experiences [35] as illustrated in Figure 3 This aspect puts mastery as in the same level of 
learning activities. For example, one might learn new skills, achieve goals, receive feedback and improve his/her abilities.

In essence, efficient games give to the player the ability to master, which could interfere in the player's journey or the lifecycle of the application [6]. In gamified systems that depend on novelty and dynamic responses, the concept to promote mastery within the system should be considered. For this reason, actions that include time-based patterns, visibility of progress, social actions and emotional engagement through curiosity, delight and fun are usually implemented in applications that aim mastery [14].

\section{Discussion}

Although gamification is one alternative to build engaging relationships with people, its effect is momentary [6],[10]. Sustaining the gamification effect is becoming a challenge for designers [14]. In this scenario, it is necessary to combine motivational theories and gamification principles to retain the users' attention in the long term.

The proposed framework SGI is a way to integrate purpose, mastery, relatedness and flow to competence and time, as a guideline for designers that want to create relevant experiences that people will be engaged to in the long-term. The SGI framework can be applied to any stage of designing or evaluating the gamified app/system such as:

- Before designing the gamified application (developing stage)

- After designing the gamified application (evaluation stage)

\subsection{Developing stage}

The SGI framework could be applied to ensure the creation of a user-centered tool, in which all the users' needs and requirements are respected. For example, for the purpose element, it is important to include the user's motivations, whereas for the mastery element it is essential to consider the user's objectives. All the elements should be in a balance. It is also important to combine the objectives of the application with the user's intentions. The application design might have elements that induce the user to get better and keep the interest over a certain time, giving the player something that allows him to master and become better in each level.

\subsection{Evaluation stage}

On the other hand, if SGI is implemented after the application design, it could work as an evaluation tool. For example, if the company has built one gamified system before, the SGI framework could give insights about how to make it work in the longterm, involving the user with more efficiency. Once the application is built, the SGI could help designers to evaluate and increment the gamified application. The framework could be helpful to analyze the elements of the current gamified application and identify the missing parts. For example, if the application is not respecting the user's purpose, it should be changed. Or if the feedback system is not helping the user to master in one task, then the system needs to be modified.

The conditions for the SGI to happen are related to the elements that the application will have. For example, in order to build mastery, it is possible that the gamified system provides challenges that in turn provide meaningful rewards to the user, together with feedback loops. Thus, it is important to conduct a strong user research and learn from the player while the player interacts with the application. Moreover, it is possible to expand the area of user research regarding the elements proposed by the SGI framework, in order to understand the user's perspectives, motivations and pain points. By definition, user research is the study of goals, needs and abilities of the user to perform one action, with the aim to create or improve tools to benefit user's lives [36]. Moreover, in user research and user experience, this could be applied on the definition of personas, scenarios and user stories. User research could be a way to collect this necessary data in order to build a gamified system that will be sustainable, respecting all the SGI elements. Consistently, user research, iterations, design and refinement are also part of product development design and should be considered in the implementation stage while designing products for behavior change [37].

The alternatives of the application of the SGI are vast. The benefits of this framework lie on the field of behavior design, helping designers to make better interactions for people.

The SGI framework could assist designers in several ways. First, it can give them with the ability to create engaging applications that draw upon intrinsic motivation. Second, it can provide elements that relatable to the user, through the focus on user's skills and expectations.

There are many scenarios in which this can be explained. Students could choose to learn a subject because they want and not because of external rewards. Consumers could interact with a brand because they are emotionally related to it, and not because of external incentives. Patients could choose to change their behaviors because they want a healthier life, and not because they might get an extrinsic reward. For that, it is important that designers understand what would keep students motivated, what would make consumers related to a brand and what would change patients' behaviors. Thus, to ensure this, it will be necessary to understand the users' needs, background and expectations in each category, such as purpose, competence or skills, relatedness and motivations. 
Table 3 The scenarios for the application of the SGI framework

\begin{tabular}{|c|c|c|}
\hline & Developing stage & Evaluation stage \\
\hline 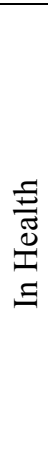 & $\begin{array}{l}\text { Patients would } \\
\text { interact with the } \\
\text { application because } \\
\text { they want, building } \\
\text { intrinsic motivation. } \\
\text { Example: The } \\
\text { application has } \\
\text { meaningful } \\
\text { challenges and } \\
\text { goals }\end{array}$ & $\begin{array}{l}\text { The gamified system } \\
\text { could inform about the } \\
\text { elements should be } \\
\text { improved in the } \\
\text { application. Example: } \\
\text { The goals of the } \\
\text { application does not } \\
\text { match the patient's } \\
\text { expectations, thus it } \\
\text { needs to improve } \\
\text { purpose }\end{array}$ \\
\hline 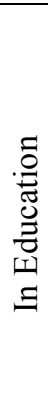 & $\begin{array}{l}\text { Students would } \\
\text { interact with the } \\
\text { application because } \\
\text { they are intrinsically } \\
\text { motivated. } \\
\text { Example: The } \\
\text { application allows } \\
\text { students to master } \\
\text { and progress in } \\
\text { specific subjects }\end{array}$ & $\begin{array}{l}\text { The gamified system } \\
\text { could inform the } \\
\text { exactly aspects that } \\
\text { need to be improved in } \\
\text { the application. } \\
\text { Example: The } \\
\text { application does not } \\
\text { respect the student's } \\
\text { skills, thus it needs to } \\
\text { improve competence }\end{array}$ \\
\hline 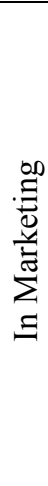 & $\begin{array}{l}\text { Consumers would } \\
\text { interact with the } \\
\text { system because they } \\
\text { are emotionally } \\
\text { related to it. } \\
\text { Example: The } \\
\text { application permits } \\
\text { users to share their } \\
\text { opinions with } \\
\text { friends and promote } \\
\text { the brand in the } \\
\text { community }\end{array}$ & $\begin{array}{l}\text { The gamified system } \\
\text { could inform the } \\
\text { aspects that should be } \\
\text { improved. Example: } \\
\text { The application does } \\
\text { no contain elements } \\
\text { that promote } \\
\text { relatedness, thus it } \\
\text { needs to improve social } \\
\text { interactions }\end{array}$ \\
\hline
\end{tabular}

\section{Conclusion}

This paper proposed a framework with the aim to increase the sustainability of a gamification impact. The SGI framework contains five main elements and other sub-elements. These are flow, relatedness, purpose, autonomy and mastery, which work together in order to balance and design the best experience to the user in different scenarios.

The goal of this framework is to be a guide for future application of gamification in any field, such as health, marketing, business, work environments and learning. In the future, we aim to apply this framework, evaluate it, and study its effects further. Moreover, it will be applied in two stages of the design process of gamified applications, development stage and evaluation stage. Thus, helping designers improve their ability to promote sustainable gamified systems for people.

\section{Acknowledgements}

- A. Acknowledges sponsorship by King Abdullah Foreign Scholarship Program, Saudi Arabia

- V. W. V. thanks the program Science Without Borders, managed by Coordenação de Aperfeiçoamento de Pessoal de Nível Superior (CAPES), Brazil, for grants provided for this research

\section{References}

[1] S. Deterding, M. Sicart, L. Nacke, K. O'Hara, and D. Dixon, "Gamification: Using Game Design Elements in Non-Gaming Contexts," in CHI'11 Extended Abstracts on Human Factors in Computing Systems, 2011, pp. 2425 2428.

[2] G. Zichermann and J. Linder, Game-Based Marketing: Inspire Customer Loyalty Through Rewards, Challenges, and Contests. Wiley, 2010.

[3] K. Huotari and J. Hamari, "Defining gamification: a service marketing perspective," in Proceeding of the 16th International Academic MindTrek Conference, 2012, pp. 17-22.

[4] K. M. Kapp, The Gamification of Learning and Instruction: Game-based Methods and Strategies for Training and Education. John Wiley \& Sons, 2012, p. 302.

[5] Bunchball Inc, "Gamification: A Cure For The Healthcare Industry?," 2013.

[6] S. Nicholson, "A User-Centered Theoretical Framework for Meaningful Gamification A Brief Introduction to Gamification Organismic Integration Theory Situational Relevance and Situated Motivational Affordance," in Games +Learning+Society 8.0, 2012.

[7] D. Pink, Drive: The Surprising Truth about What Motivates Us. Riverhead Hardcover, 2009.

[8] M. Csikszentmihalyi, Flow: The psychology of optimal performance. New York: Harper and Row, 1990.

[9] H. Qin, P.-L. Patrick Rau, and G. Salvendy, "Measuring Player Immersion in the Computer Game Narrative," Int. J. Hum. Comput. Interact., vol. 25, no. 2, pp. 107-133, Feb. 2009.

[10] J. Koivisto and J. Hamari, "Demographic Differences in Perceived Benefits from Gamification," Comput. Human Behav., vol. 35, pp. 179-188, Jun. 2014.

[11] K. Werbach, For the Win: How Game Thinking Can Revolutionize Your Business. Wharton Digital Press, 2012, p. 148.

[12] D. N. Crowley, J. G. Breslin, P. Corcoran, and K. Young, "Gamification of Citizen Sensing Through Mobile Social Reporting," in IEEE International Games Innovation Conference, 2012, pp. 1-5. 
[13] G. Zichermann and C. Cunningham, Gamification by Design: Implementing Game Mechanics in Web and Mobile Apps. O'Reilly Media, Inc., 2011, p. 208.

[14] F. L. Law, Z. M. Kasirun, and C. K. Gan, "Gamification Towards Sustainable Mobile Application," in 2011 Malaysian Conference in Software Engineering, 2011, pp. $349-353$.

[15] J. McGonigal, Reality Is Broken: Why Games Make Us Better and How They Can Change the World, 2011th ed., vol. 22. Penguin Books, 2011.

[16] B. J. Fogg, "Persuasive Technology: Using Computers to Change What we Think and Do," Ubiquity, Dec-2002.

[17] M. Rozenfeld, "Gaming in the Workplace," The Institute - The IEEE News Source, 2014. [Online]. Available:http://theinstitute.iee.org/technology-focus/ technology-topic/gaming-in-the-workplace. [Accessed: 30Aug-2014].

[18] K. Krippendorff, "Intrinsic Motivation and HumanCentered Design," Theor. Issues Ergon. Sci., vol. 5, pp. 4372,2004

[19] D. Wortley, "Gamification and geospatial health management," in IOP Conference Series: Earth and Environmental Science, 2014, vol. 20.

[20] N. Lazzaro, "Why We Play Games: Four Keys to More Emotion Without Story," in Game Developers Conference, 2004.

[21] R. Ryan and E. Deci, "Intrinsic and Extrinsic Motivations: Classic Definitions and New Directions.," Contemp. Educ. Psychol., vol. 25, no. 1, pp. 54-67, Jan. 2000 .

[22] C.-L. Hsu and H.-P. Lu, "Why do people play on-line games? An extended TAM with social influences and flow experience,” Inf. Manag., vol. 41, no. 7, pp. 853-868, Sep. 2004.

[23] B. Bostan, U. Kaplancali, K. Cad, and A. Yerlesimi, "Explorations in Player Motivations: Game Mechanics," in GAMEON, 2009.

[24] J. McGonigal, "Engagement Economy: the future of massively scaled collaboration and participation," California, United States, 2008. [25] P. Newbery and K. Farnham, Experience Design: A Framework for Integrating Brand, Experience, and Value, 1 edition. John Wiley \& Sons, 2013.

[26] L. G. Zomerdijk and C. a. Voss, "Service Design for Experience-Centric Services," J. Serv. Res., vol. 13, no. 1, pp. 67-82, Dec. 2009.
[27] J. van Doorn, K. N. Lemon, V. Mittal, S. Nass, D. Pick, P. Pirner, and P. C. Verhoef, "Customer Engagement Behavior: Theoretical Foundations and Research Directions," J. Serv. Res., vol. 13, no. 3, pp. 253-266, Aug. 2010.

[28] D. Johnson and J. Wiles, "Effective Affective User Interface Design in Games," Ergonomics, vol. 46, no. 13-14, pp. 1332-45, 2003.

[29] M. Csikszentmihalyi, The Evolving Self: A Psychology for the Third Millennium. New York: HarperCollins, 1993.

[30] J. Bizzocchi, M. A. Ben Lin, and J. Tanenbaum, "Games, Narrative and the Design of Interface," Int. J. Arts Technol., vol. 4, no. 4, pp. 460-479, 2011.

[31] P. Sweetser and P. Wyeth, "GameFlow : A Model for Evaluating Player Enjoyment in Games," vol. 3, no. 3, pp. 1-24, 2005.

[32] F. Groh, "Gamification: State of the art definition and utilization," in Proceedings of the 4th Seminar on Research Trends in Media Informatics, 2012, pp. 39-45.

[33] M. Hassenzahl, S. Diefenbach, and A. Goritz, "Need, Affect, and Interactive products - Facets of User experience," Interact. Comput., vol. 22, no. 5, pp. 353-362, 2010.

[34] J. Hamari, "Transforming homo economicus into homo ludens: A field experiment on gamification in a utilitarian peer-to-peer trading service," Electron. Commer. Res. Appl., vol. 12, no. 4, pp. 236-245, Jul. 2013.

[35] A. J. Kim, “The Player's Journey: Designing Over Time," Amy Jo Kim. Games, Apps \& Services That Bring People Together, 2012. [Online]. http:// amyjokim.com/2012/09/14/the-players-journeydesigning-over-time/. [Accessed: 23-Aug-2014].

[36] J. Sauro and J. R. Lewis, Quantifying the User Experience: Practical Statistics for User Research. Morgan Kaufmann Publishers Inc., 2012.

[37] S. Wendel, Designing for Behavior Change: Applying Psychology and Behavioral Economics, 1st editio. O'Reilly Media, Inc., 2013. 